\title{
Protótipo de um Sistema de Comunicação Acústico para Fins Didáticos
}

\author{
Lucas B. D. Saraiva, Daniel R. de Luna, Vicente A. de Sousa Jr.
}

\begin{abstract}
The various stages of a communication system are often not well explored in the academic environment due to the cost of radiofrequency equipment to put into practice the knowledge discussed in the classroom. The purpose of this work is to present an acoustic communication system prototype using script programming language, which can serve as a simple platform for software-defined radio (SDR), bringing practical experience and interactivity to the student learning digital modulation. The experiment may spark the idea of using everyday devices to compose handmade communications systems, by using devices such as a headset (as a transmitter) and microphone (as a receiver). As a case study, an image is transmitted by mechanical waves in the audible range, visualizing the signal in time and frequency, and also discussing aspects of synchronization and response to the channel impulse.
\end{abstract}

\section{INTRODUÇÃO}

As novas diretrizes curriculares nacionais (DCN) de engenharia [1] definem que haja um aprendizado a partir de metodologias ativas, motivando o aluno a participar da resoluções de problemas práticos. Além disso, a DCN propõe, além da multidisciplinaridade, o uso do conceito de interdisciplinaridade e transdisciplinaridade, abordando as componentes curriculares do curso de engenharia de forma interconectada e cooperativa, como parte de um só conhecimento.

A proposta deste trabalho é apresentar o protótipo de um sistema de comunicação acústica capaz de transmitir uma imagem, como forma de despertar a participação e interação de alunos em atividades integradoras de componentes curriculares da área de telecomunicações. A ideia é motivar o aprendizado e trazer experiência com os problemas e limitações reais de sistemas de comunicação, também dando a oportunidade de o aluno buscar em conteúdos ministrados em sala a resolução de problemas comuns, na medida em que for desenvolvendo o protótipo. Sendo assim, é apresentando um protótipo simples de um sistema de comunicação, utilizando materiais do cotidiano dos alunos: um fone de ouvido, um microfone e um computador pessoal. O alvo é empregar uma estratégia de modulação por deslocamento de fase (BPSK, do Inglês binary phase-shift keying) de fácil implementação, que traga experiência e interação com problemas reais de um sistema de comunicação (muitas vezes negligenciados no ensino tradicional).

Ao criar um enlace de comunicação acústica para transmissão e recepção de uma imagem, o protótipo serve para demostrar

Lucas B. D. Saraiva é vinculado ao curso de Engenharia Elétrica da Universidade Federal do Rio Grande do Norte (UFRN), Natal, RN. E-mail: lucas_saraiva@ufrn.edu.br. Os autores Daniel R. de Luna e Vicente A. de Sousa Jr. são Programa de Pós-graduação em Engenharia Elétrica (PPgEEC) da Universidade Federal do Rio Grande do Norte (UFRN), Natal, RN. E-mails: \{danielro,vicente.sousa\}@ufrn.edu.br. Este trabalho foi realizado com apoio da Coordenação de Aperfeiçoamento de Pessoal de Nível Superior - Brasil (CAPES) - Código de Financiamento 001. visualmente o efeito da taxa de erro de bits (BER, do Inglês bit error rate). Foi escolhida uma fonte de dados grande o suficiente para que haja a necessidade de realizar mais de um sincronismo ao longo da transmissão, e também propiciar uma quantidade de bits que resultasse em acurácia na estimação da probabilidade de erro de bit por meio da BER. Segundo [2], na transmissão de uma imagem de 7 kB (56000 bits), é possível estimar probabilidades de erro da ordem de $10^{-4}$, sendo este o caso do experimento realizado neste trabalho.

\section{TRABALHOS RELACIONADOS}

Os autores de [3] apresentam uma plataforma de comunicação acústica definida por software usando o MATLAB. Estes buscam avaliar o desempenho do sistema em termos de BER, considerando a variação de alguns parâmetros na simulação e no ambiente real. Foi realizada a transmissão de uma imagem usando modulações BPSK, QPSK,16-QAM e 256-QAM, com alto-falantes e microfones comerciais em distâncias variando de 20 a $100 \mathrm{~cm}$. Os autores de [4] trabalham em um modelo de modem definido por software para comunicações acústicas submarinas, com o objetivo de ter um dispositivo capaz de se adaptar às condições do meio de transmissão. Já [5] apresenta um sistema simples, usando OFDM acústico, para transmitir pequenos textos por cerca de 1 a 2 segundos. O sistema atinge taxa de transmissão de $1 \mathrm{kbps}$, ao ser empregado um algoritmo de controle de potência. Em [5], um sistema OFDM acústico foi implementado em um telefone celular, usando o alto-falante e o microfone do próprio aparelho como transmissor e receptor, respectivamente. Finalmente, em [6], os autores propuseram um sistema MIMO acústico usando vários alto-falantes e vários microfones, empregando técnicas como cancelamento de diafonia e cancelamento de eco.

Os trabalhos mencionados anteriormente, mesmo sendo baseados em comunicação acústica, SDR e usando dispositivos do cotidiano, não têm o caráter de expor os problemas construtivos dos protótipos. Assim, mesmo disponibilizando um aprendizado para quem os lê, tais artigos almejam a avaliação de desempenho de alguma funcionalidade do sistema de comunicação acústico, e não a apresentação didática das partes que compõem o sistema. Este último é o principal foco deste artigo, e constitui sua principal contribuição. Essa contribuição se baseia na crença que os trabalhos baseados em protótipos de sistema de comunicação em SDR possibilitam a análise de cada etapa do sistema de forma intuitiva, tanto para a construção quanto para identificação de erros que surgirão à medida em que o sistema for sendo construído, se tornando uma ferramenta muito acessível ao ensino-aprendizado.

\section{PROTÓTIPO CONSTRUÍDO}

O protótipo foi construído para operar na faixa de frequência audível, que compreende $20 \mathrm{~Hz}$ a $20 \mathrm{kHz}$. Além disso, o 
estudo de caso apresentado na Seção IV adotou $10 \mathrm{kHz}$ como frequência de operação e largura de banda de $20 \mathrm{kHz}$. A frequência de amostragem adotada é $44,1 \mathrm{kHz}$ (comum em placas de som de computadores pessoais) e o modelo de duplexação é o simplex, em que um lado é só transmissor e o outro só receptor. O protótipo construído, ilustrado na Fig. 1, baseia-se em ensinamentos de [7]. As próximas seções são dedicadas a detalhar a implementação de cada bloco.

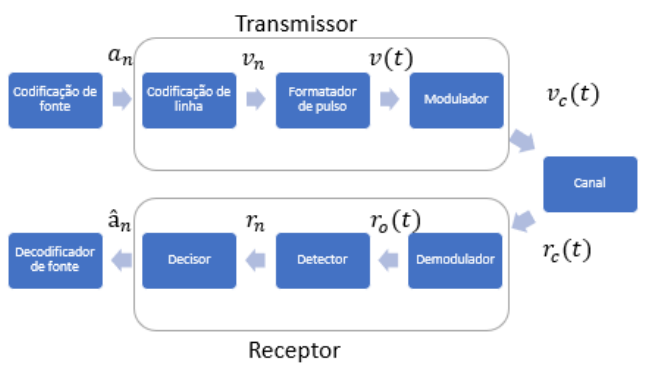

Fig. 1. Diagrama de blocos do protótipo construído.

\section{A. Transmissor}

O processo de formatação da fonte (aqui representado no bloco do codificador de fonte) é responsável por entregar uma sequência de bits (mensagem), $\underline{a}=\left[\begin{array}{lllll}a_{0} & a_{1} & a_{2} & \ldots & a_{N_{a}-1}\end{array}\right]$, tal que $a_{n} \in\{0,1\}$ é o $n$-ésimo bit da mensagem.

A Fig. 2 foi usada como fonte de informação a ser codificada e, em seguida, ser transmitida. O protótipo é baseado no conteúdo bruto dos dados, i.e., nos bits que carregam a informação da imagem propriamente dita. Tais bits são a composição de 3 matrizes juntas, referentes às cores vermelho, verde e azul (RGB), formando as cores de cada ponto (pixel) da imagem. Por ser uma imagem digital, os elementos destas matrizes são naturalmente amostrados e quantizados [8].$$
\text { GppComi }
$$

Fig. 2. Imagem a ser codificada para transmissão.

A quantização é feita com 8 bits (cada pixel representado de 0 a 255), e a sua resolução é de 269 por 91. Assim, a figura pode ser representada como um único vetor binário como na Equação 1:

$$
\mathbf{R G B}=\left[\begin{array}{lllllll}
R_{1,1} & \ldots & R_{K, M} \| G_{1,1} & \ldots & G_{K, M} \| B_{1,1} & \ldots & B_{K, M}
\end{array}\right],
$$

sendo $\mathbf{R}, \mathbf{G}$ e $\mathbf{B}$ as matrizes correspondentes ao vermelho, verde e azul, respectivamente; e os valores $K$ e $M$ representando os valores máximos dos índices verticais e horizontais dos pixels da imagem, respectivamente.

Contudo, além dos dados brutos da imagem, é necessário que seja transmitida informação adicional sobre o tamanho da imagem para que o receptor consiga reconstruí-la. Tais dados são chamados de metadata. Adicionalmente, foram inseridas palavras de sincronismo em cada $x$ amostras de dados. A palavra de sincronismo consiste em uma sequência binária de 52 amostras, conhecida tanto pelo transmissor quanto pelo receptor.
Sua principal função é indicar ao receptor qual é a primeira amostra do quadro (frame) de transmissão, que será abordado mais detalhadamente na Seção III-B. O número de amostras do metadata e da palavra de sincronismo são conhecidos pelo receptor. Pelo metadata, é possível calcular quantas amostras de dados brutos tem a imagem, portanto o receptor também é capaz de identificar o comprimento de todo o frame. A sequência de dados transmitidos é ilustrada na Fig. 3, a qual mostra que o metadata é precedido da palavra de sincronismo, e sucedido pela parte inicial dos dados brutos da imagem.

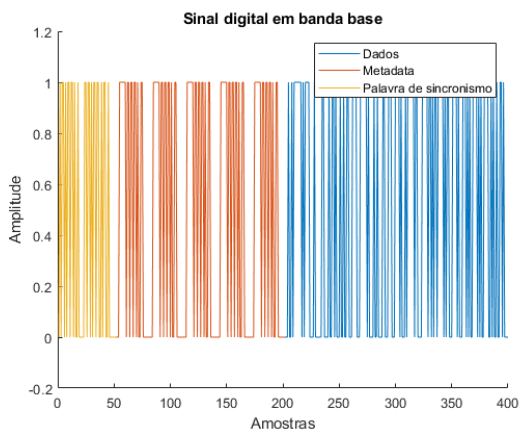

Fig. 3. Protocolo de comunicação (banda base).

$\mathrm{Na}$ codificação de linha (modulação em banda base), os dados binários de entrada $a_{n}$ são transformados em um sinal de amplitudes discretas. O mapeamento das amostras depende do esquema a ser empregado [7]. Para este trabalho, foi adotado a sinalização antipodal Non-Return-to-Zero (NRZ).

A codificação de linha é responsável por gerar o sinal digital contínuo no tempo a partir das amplitudes do mapeador de símbolo $\underline{v}=\left[\begin{array}{llll}v_{0} & v_{1} & \ldots & v_{N_{a}-1}\end{array}\right]$, geralmente acompanhada de sobreamostragem, para controlar a forma do espectro do sinal transmitido. Sendo feita a sobreamostragem (oversampling), o sinal resultante é $v(t)=\sum_{n=0}^{N_{a}-1} v_{n} h_{T}(t-n T)$, sendo $T$ a duração de cada pulso, e $h_{T}(t)$ é a saída do o filtro formatador do pulso.

O filtro formatador de pulso pode ser escolhido para controlar o espectro do sinal transmitido, além de ser escolhido de forma a proteger os símbolos de interferência intersimbólica (ISI) [9]. Para este trabalho, foi utilizado o pulso cosseno levantado, com $\alpha=0,25$ de fator de roll-off.

Finalizada a etapa de codificação de linha, começa a modulação em banda passante. Nessa etapa, ocorre a elevação da frequência do sinal para a faixa de transmissão desejada (neste caso, a faixa audível). Para isso, a modulação do sinal de saída $v(t)$ é representada como na Equação 2:

$$
v_{c}(t)=v(t) \cos \left(2 \pi f_{c} t\right),
$$

tal que $f_{c}$ é a frequência da portadora.

Com isso, o sinal já está apto a ser transmitido. Porém, o receptor precisa identificar, dentre as amostras coletadas, qual é a amostra inicial referente ao sinal modulado. As perturbações do canal (incluindo ruído e interferências) excluem a possibilidade de identificar o começo da informação útil pela amplitude (e.g., por um nível maior que um determinado valor), visto que a potência recebida pode variar bruscamente, devido a um ruído impulsivo, por exemplo, podendo ter picos de amplitudes que não correspondem necessariamente ao começo da recepção de dados úteis. Portanto, a tratativa tradicional para 
esse tipo de problema é concatenar ao sinal modulado um sinal conhecido (preâmbulo) que, quando o receptor identificá-lo, começará a demodular o sinal. Além do preâmbulo, também foi enviada uma portadora $c(t)$ para recuperar a informação de fase. A necessidade dessa portadora é detalhada na Seção III-B.

A Fig. 4 mostra a sequência final do sinal transmitido. É importante relembrar que existem dois sinais de sincronismo: um em banda base (palavra de sincronismo da Fig. 3), para identificar os dados úteis da imagem e o metadata; e outro em banda passante (preâmbulo da Fig. 4) para identificar o começo do sinal modulado.

Foram atribuídas também amplitudes diferentes para cada parte do sinal em banda passante. O preâmbulo tem maior amplitude para facilitar sua detecção por autocorrelação.

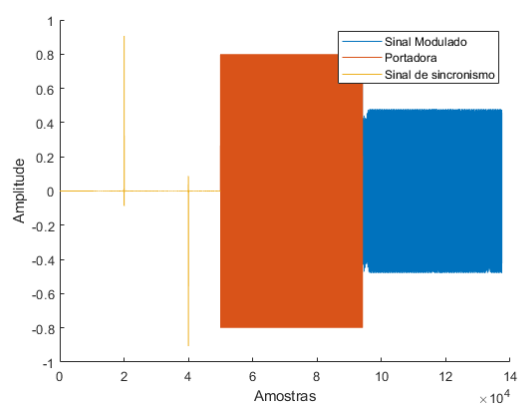

Fig. 4. Sinal transmitido

Assim, o sinal transmitido é $v_{c s n}(t)=\left[\begin{array}{lll}s_{n}(t) & c(t) & v_{c}(t)\end{array}\right]$ em que $v_{c}(t)$ é o sinal de dados modulado descrito na Equação 2 ; $c(t)$ é a portadora para recuperação de fase no receptor; e $s_{n}(t)$ é o preâmbulo.

Entre a transmissão e a recepção, o sinal sofre distorções do canal (com resposta ao impulso $h(t)$ ) e é sujeito as respostas das camadas físicas de transmissão $\left(h_{T X}(t)\right)$ e recepção $\left(h_{R X}(t)\right)$ (alto-falante e microfone). $\mathrm{O}$ sinal no receptor pode ser descrito pela Equação 3.

$$
r_{c}(t)=v_{c s n}(t) * h(t) * h_{T X}(t) * h_{R X}(t)+n(t)+i(t)
$$

Além do canal e das camadas físicas, o sinal experimenta a presença de ruídos aditivos (representados por $n(t)$ ) e de interferências (representadas por $i(t)$ ) de sinais de fontes externas transmitindo na mesma frequência e ao mesmo tempo.

\section{B. Receptor}

O primeiro passo para fazer a demodulação em banda passante é encontrar a primeira amostra correspondente ao sinal transmitido. Para isso, o sinal de preâmbulo foi concatenado ao sinal transmitido. Ele possui uma autocorrelação bem caracterizada, ou seja, seu pico de autocorrelação é bem definido, como mostra a Fig. 5 (a). Já a Fig. 5 (b) mostra a autocorrelação entre o preâmbulo $s_{n}(t)$ e o sinal recebido $r_{c s n}(t)$. É possível identificar $\operatorname{lag}_{n}$ amostras entre o pico de autocorrelação e a primeira amostra do sinal modulado.

Como descrito na Equação 3, o canal e as camadas físicas distorcem o sinal transmitido, fazendo com que o pico de correlação cruzada de $s_{n}(t)$ e $r_{c s n}(t)$ seja deslocado em $i$ amostras, tal que $i \in \mathbb{Z}$. Portanto, o receptor está sujeito a errar em $i$ amostras o início exato do sinal transmitido, com o

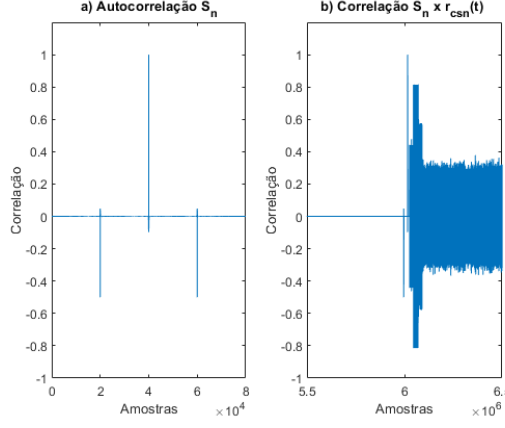

Fig. 5. (a) Pico de autocorrelação de $s_{n}$. (b) Correlação cruzada de $r_{c s n}$ com $s_{n}$.

valor correto de $\widehat{\operatorname{lag}_{n}}=\operatorname{lag}_{n}+i$. Para corrigir esse erro, após o receptor encontrar o pico de correlação como na Fig. 5 (b), este varrerá uma faixa de $-200<i<200$, demodulando para cada valor de $i$ as primeiras amostras do sinal, verificando se o sinal demodulado corresponde à palavra de sincronismo, como definido no protocolo de banda base na seção III-A. O valor de $i$ que satisfizer a condição será compreendido como o erro da correlação e usado para calcular o valor correto de $\widehat{\operatorname{lag} n}$. Quanto maior a palavra de sincronismo, menor será a probabilidade de erro sendo, para 52 amostras, da ordem de $10^{-16}$.

De posse de $\widehat{l a g_{n}}$, do comprimento de $s_{n}(t)$ e do número de amostras da portadora, pode-se encontrar o início do sinal modulado em banda passante, como mostra a Fig. 4.

Para demodulação coerente, é feito a estimação de fase. $\mathrm{O}$ sinal $c(t)$ acrescentado a $r_{c s n}(t)$ é descrito por $c(t)=$ $\cos \left(2 \pi f_{c} t+\theta(t)\right)$, sendo $\theta(t)$ a diferença de fase do transmissor em relação ao receptor. Essa fase surge por que não há sincronismo entre o tempo de lançamento de uma amostra do transmissor com o tempo que o receptor registra a amostra, criando assim um atraso angular. Para a detecção da fase $\theta(t)$, é usado o método de Phase-Locked Loop (PLL) descrito em [10], aproveitando as vantagens de um sistema SDR. No detector de fase é gerado o sinal da Equação 4, análogo à saída de um oscilador controlado por tensão (VCO, do inglês Voltage Controled Oscilator).

$$
x(t)=-\operatorname{sen}\left(2 \pi f_{c} t+\widehat{\theta}(t)\right)
$$

Fazendo o produto dos sinais $x(t)$ e $c(t)$, tem-se uma saída dada por $e(t)=c(t) x(t)=$ $\frac{1}{2}\left(\operatorname{sen}(\theta(t)-\widehat{\theta}(t))-\operatorname{sen}\left(4 \pi f_{c} t+\theta(t)+\widehat{\theta}(t)\right)\right), \quad$ em que $e(t)$ é o erro composto por uma componente de alta frequência $-\operatorname{sen}\left(4 \pi f_{c} t+\theta(t)+\widehat{\theta}(t)\right)$ e uma componente DC $\operatorname{sen}(\theta(t)+\widehat{\theta}(t))$, cuja magnitude corresponde à diferença de fase do sinal recebido e o gerado no receptor. Assim, ao remover a componente de alta frequência com um filtro passa baixa, representado por $L P F\{\}$, o erro de fase pode ser expresso por $e_{\theta}(t)=\theta(t)-\widehat{\theta}(t)=$ asen $(2 . L P F\{e(t)\})$, sendo $e_{\theta}(t)$ o erro de fase em radiano, e asen, a função inversa de seno. Na prática, ajusta-se o valor de $\widehat{\theta}(t)$ de forma a zerar o valor de $e_{\theta}(t)$.

Em seguida, o demodulador recebe o sinal em banda passante e o transforma novamente em banda base, resultando em $r_{o}(t)=r_{c}(t) \cos \left[2 \pi f_{c} t+\widehat{\theta}(t)\right]$. O sinal em banda base é passado para o detector, responsável por filtrar e sub-amostrar o sinal recebido $r_{o}(t)$. O filtro receptor, cuja resposta ao impulso é 
dada por $h_{R}(t)$, age como filtro passa baixa para remover as componentes de alta frequência que surgem na demodulação, suprimindo também possíveis ruídos introduzidos no canal por não ser ideal [7]. Neste trabalho, o detector usa a técnica de filtro casado, cuja resposta ao impulso é da forma $h_{R}(t)=h_{T}(T-t)$. Sua saída $r(t)$ é expressa por $r(t)=\int_{-\infty}^{\infty} r_{o}(t-\tau) h_{R}(\tau) d \tau$. Esse procedimento maximiza a $S N R$ na saída do filtro casado.

Em seguida, o sinal é subamostrado, gerando uma saída $r_{n}$, que é entregue ao decisor (última etapa da recepção). O decisor é responsável por determinar o valor de cada bit. Se $r_{n} \geq 0$, $\widehat{a}_{n}=0$, caso contrário $\widehat{a}_{n}=1$.

Se tudo ocorrer como esperado, $\widehat{a}_{n}$ deverá ser igual a $a_{n}$. Posteriormente, a fonte de dados é reconstruída, montando as matrizes do RGB, desfazendo a transformação da Equação 1.

\section{Estudo DE CASO}

\section{A. Setup Experimental}

Os experimentos foram realizados em um setup experimental simples, que consiste de um computador desktop da marca Dell e um computador portátil (notebook) da marca Sony. No desktop foi instalado o transmissor, com um fone de ouvidos servindo como elemento radiante. No notebook foi instalado o receptor, com o sinal acústico sendo captado pelo seu microfone interno. Para controlar a perda de percurso (que é um objeto de estudo futuro), transmissor e receptor foram dispostos bem próximos.

Em cada experimento, o notebook grava um arquivo com amostras de som, que depois são processadas pelo receptor. Antes de iniciar a transmissão do som, inicia-se a gravação no lado do receptor, para evitar que o transmissor inicie a comunicação primeiro e o receptor não grave as amostras iniciais. A duração da gravação vai depender da duração da transmissão e, como o processo de recepção não é feito em tempo real, é necessário determiná o tempo de gravação previamente para o receptor. Assim, é possível planejar quanto tempo de áudio é necessário gravar no receptor.

\section{B. Experimento de Referência}

Uma primeira transmissão foi realizada como caso de referência. A imagem da Fig. 2, cujo tamanho é de $7 \mathrm{kB}$, foi transmitida em condições de isolamento acústico. Devido a pequena distância entre transmissor e receptor, a taxa de erro de bit foi a menor possível $(B E R=0)$, portanto, a imagem reconstruída no receptor foi idêntica à transmitida.

Para fins didáticos, outros sinais analisados foram os espectros dos sinais transmitido e recebido. A comparação feita na Fig. 6 ilustra que houve ganho nas componentes de baixa frequência e atenuação nas de alta frequência. Notou-se também que o erro de deslocamento do cálculo da autocorrelação (valor $i$, explicado na Seção III-B) variou devido a natureza de $s_{n}(t)$ e também com as primeiras amostras de $v_{c s n}(t)$. $\mathrm{O}$ valor de $i$ permaneceu entre 5 a 15 amostras atrasado, ou seja, o receptor demodula $i$ amostras depois da detecção do pico de autocorrelação. Nestas condições, infere-se que o protocolo de recepção tem uma folga na varredura de $i$, visto que ela é feita em 400 amostras.

\section{Formatador de pulso}

O formatador de pulso é decisivo para o sucesso do sistema de comunicação digital, visto que também define o espectro

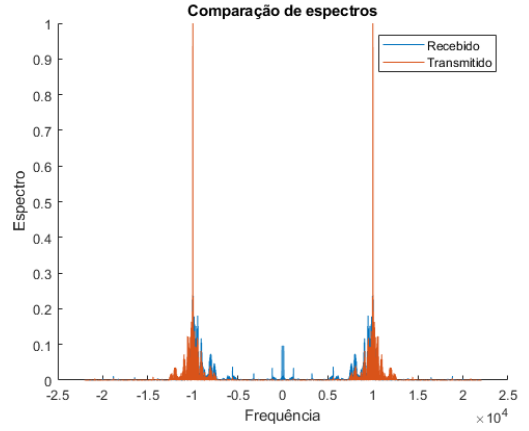

Fig. 6. Espectros normalizados dos sinais transmitido e recebido.

do sinal $v_{c}(t)$. Foi feita uma comparação dos espectros do formatadores de pulso retangular e cosseno levantado com fator de roll-off $\alpha=0,25$ na Fig. 7 .

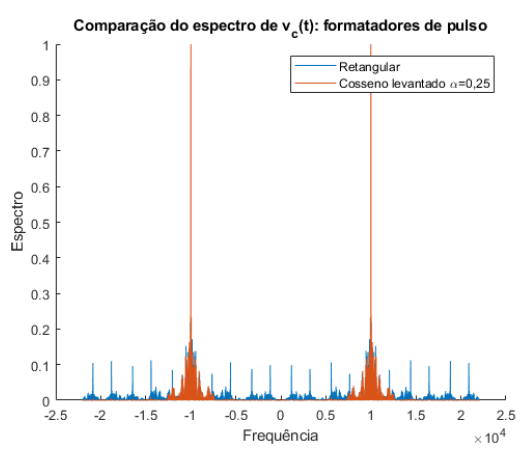

Fig. 7. Espectro do sinal em banda passante $v_{c}(t)$ com o formatador de pulso retangular e com cosseno levantado.

Como esperado, o formatador de pulso retangular possui maior dependência da banda do canal que o cosseno levantado. Como o espectro do pulso retangular é teoricamente infinito, o canal de comunicação (que é limitado em banda por natureza) atenua as componentes de alta frequência, piorando a qualidade do sinal recebido. Vale ressaltar que o cosseno levantado pertence à uma família de funções que matematicamente minimizam a ISI, resultando em melhor desempenho do protótipo.

Para o filtro formatador de pulso retangular e nas mesmas condições de isolamento acústico descrito na Seção IV-A, o desempenho do sistema manteve-se entorno de $B E R=10^{-4}$. Isso pode ser atribuído tanto à deformação de seu espectro quanto à presença de ISI, mostrando o quão é importante a escolha do pulso formatador para o bom desempenho do sistema. Esse é um exemplo de como o protótipo deste artigo proporciona o aluno a experimentar na prática os conceitos vistos matematicamente em sala de aula.

\section{Interferência}

Com o mesmo áudio gravado na Seção IV-A, foi calculado a sua potência média como $P_{s}=\frac{1}{N} \sum_{1}^{N}|s(n)|^{2}$, sendo $P_{s}$ a potência média de um sinal $s(n)$ e $N$ o número de amostras do sinal.

De posse da potência média do sinal recebido, foi possível gerar artificialmente um sinal de interferência, controlando a relação sinal-interferência $(S I R)$ de recepção. A interferência gerada é do tipo AWGN, gerando valores de 
$S I R=\left[\begin{array}{llll}5 & 1 & -5 & -10\end{array}\right]$ dB. Esses experimentos geraram os resultados da Fig. 8.

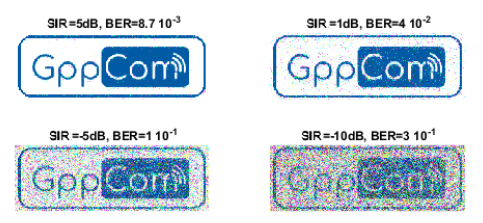

Fig. 8. Variação da SIR com suas respectivas BERs.

Como o esperado, a interferência impacta na qualidade de recepção da imagem. Como a interferência foi modelada como AWGN, a qualidade da imagem é distorcida de forma aleatória ${ }^{1}$ ao ponto de deixá-la cada vez menos legível. Percebe-se também que quanto menor a $S I R$, mais a imagem se assemelha à imagem de uma televisão analógica fora de sintonia (com os típicos "chuviscos").

É importante salientar que na própria gravação, o receptor recebe tanto o ruído externo quanto seu próprio ruído térmico. Portanto, os resultados acima são de uma aproximação da SIR. Isso se deve a presença de circuitos eletrônicos e ao fato da isolação acústica não ser perfeita.

\section{E. Sincronização}

Foram realizados experimentos variando a frequência e fase da portadora para forçar erros de sincronismo.

Para o erro de sincronismo de frequência na portadora do receptor, percebeu-se experimentalmente que para $f_{c}=10 \mathrm{kHz}$ um erro de apenas $5 \cdot 10^{-3} \mathrm{~Hz}$ é suficiente para corromper toda a demodulação.

A comunicação foi avaliada para os seguintes valores de $\Delta f_{c}=\left[\begin{array}{lllll}510^{-1} & 510^{-2} & 510^{-3} & 5 & 10^{-4}\end{array}\right] \quad H z$, com resultados mostrados na Fig. 9.

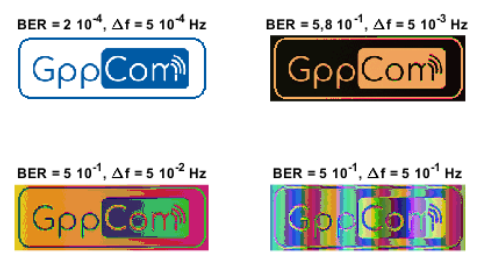

Fig. 9. Detecção da imagem para diferentes valores de $\Delta f_{c}$.

Como esse comportamento de distorção da imagem está diretamente ligado a um erro de frequência da portadora (uma distorção não branca, diferente da interferência AWGN mostrada na Seção IV-D), percebe-se uma mudança de cor da imagem para cada padrão de erro.

Para o erro de sincronismo de fase, foi usado a mesma gravação de referência mostrada na Seção IV-A. Ao invés de mostrar as imagens decodificadas, alguns valores de $\Delta \theta$ foram acrescentados com um erro na fase da portadora, sendo possível montar um gráfico de BER versus $\Delta \theta$. Assim, variando-se a fase na demodulação, obteve-se os resultados da Fig. 10.

${ }^{1}$ Devido ao caráter branco do modelo AWGN, que promove amostras descorrelacionadas e sem preferência por uma frequência específica. É possível notar que as cores da imagem não mudam, ao não ser pelos "chuviscos".

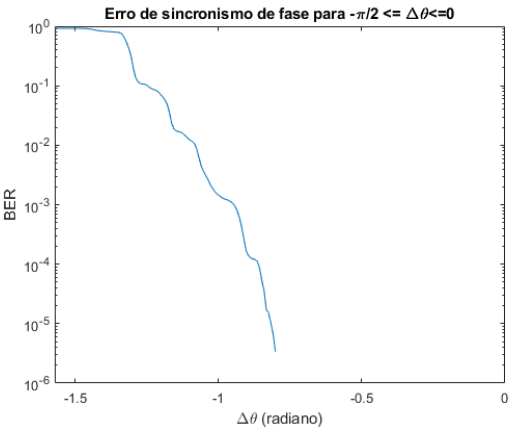

Fig. 10. Taxa de erro de bit versus erro de sincronismo de fase.

Percebe-se que, para essa boa condição de $S N R$ (isolamento acústico), existe um intervalo de erros fase relativamente grande para o qual a taxa de erro é baixa, servindo até como uma margem de segurança a erros de fase.

\section{Conclusões E trabalhos Futuros}

$\mathrm{O}$ protótipo construído neste trabalho possibilitou por em prática conceitos matemáticos de um sistema de comunicação, além de vivenciar a modularidade de sistemas, em que a saída de um módulo corresponde à entrada do módulo seguinte, desde a fonte até o destino.

Este trabalho mostrou que equipamentos simples e comuns aos alunos de engenharia podem ser uma ferramenta consolidadora de aprendizado, e ativadora da interdisciplinaridade. Este trabalho reúne conhecimentos de diversas disciplinas, como: Princípios de telecomunicações, Sistema de telecomunicações, Comunicações digitais, Antenas e propagação, Processamento digital de sinais, Comunicações sem fio e Eletromagnetismo. Também foi necessário realizar estudos autônomos de conteúdo externo às disciplinas citadas, por exemplo, relacionado a sincronismo de fase e de tempo, estimação de canal.

\section{REFERÊNCIAS}

[1] F. C. d. S. B. e. P. M. V. B. B. M. Luiz Roberto Liza Curi (Presidente) Antonio de Araujo Freitas Júnior (Relator), Antonio Carbonari Netto, Diretrizes Curriculares Nacionais do Curso de Graduação em Engenharia, MINISTÉRIO DA EDUCAÇÃO CONSELHO NACIONAL DE EDUCAÇÃO, apr 2019.

[2] J. G. Proakis and M. Salehi, "Contemporary communication systems using matlab," 1999.

[3] K. K. Airi Sakaushi, Mayuko Okano and J. Katto, "Performance evaluations of software-defined acoustic mimo-ofdm transmission," 2018 IEEE Wireless Communications and Networking Conference (WCNC), 2018.

[4] S. R. Frank Berning, Thomas Radtke and M. Motz, "A realization of the software defined radio concept in an underwater communication modem," 2014 IEEE, 2014.

[5] H. Matsuoka, Y. Nakashima, and T. Yoshimura, "Acoustic communication with ofdm signal embedded in audio," in Audio Engineering Society Conference: 29th International Conference: Audio for Mobile and Handheld Devices, Sep 2006.

[6] Y. Huang, J. Benesty, and J. Chen, "Identification of acoustic mimo systems: Challenges and opportunities," Signal Processing, vol. 86, no. 6, pp. 1278 - 1295, 2006, applied Speech and Audio Processing.

[7] S. D. of Systems and C. E. F. of Engineering, "Simulation of a simple digital communications system - laboratory 1," Carleton University, Tech. Rep., 2016.

[8] B. P. Lathi and Z. Ding, Modern Digital and Analog Communication Systems. New York : Oxford University Press, 2009., 2009, vol. 4.

[9] S. Haykin, M. Moher, and A. P. J. T. A. Jesus, Sistemas de Comunicação: Analógicos e Digitais. Bookman, 2010, vol. 5.

[10] B. Sklar, Digital Communications: Fundamentals and Applications. USA: Prentice-Hall, Inc., 1988. 